\title{
Surgical Treatment Results in Pediatric Supracondylar Humerus Fractures
}

\section{(D) Erdinç Acar ${ }^{1}$, (1) Recep Memik ${ }^{2}$}

${ }^{1}$ Department of Orthopedics and Traumatology, Konya Necmettin Erbakan University Meram Faculty of Medicine, Hand and Upper Extremity Surgery Division, Konya, Turkey

2Department of Orthopedics and Traumatology, Konya Necmettin Erbakan University Meram Faculty of Medicine, Konya, Turkey

\begin{abstract}
Aim: This study aims to evaluate the outcomes of cross fixation with Kirschner wire (K-wire) following closed reduction of displaced supracondylar humerus fractures in children.

Materials and Methods: Between December 2012 and June 2015, a total of 32 patients with suprachondral humerus fractures were retrospectively analyzed. Data including demographic data, causes and types of fracture, associated injuries, postoperative complications, radiological parameters, and cosmetic and functional outcomes were recorded.

Results: Of the patients, 24 (75\%) were male and eight (25\%) were female with a mean age of 6.5 years (range: 2 to 12 years). The mean follow-up was 19 months (range: 13 to 26 months). None of the patients developed iatrogenic vascular or nerve injuries. No postoperative complications were observed during follow-up. The functional result according to the Flynn criteria was excellent in $93.4 \%$ and good in $6.6 \%$ patients, while cosmetic results were excellent in $93.4 \%$, good in $5.2 \%$, and fair in $1.4 \%$.

Conclusion: Percutaneous fixation with K-wire following closed reduction of displaced supracondylar humerus is a reliable method which can be applied with high success rates in pediatric cases.

Keywords: Child, flynn criteria, humerus supracondylar fracture, closed reduction, kirschner wire
\end{abstract}

\section{Introduction}

Supracondylar humerus fractures are the second most common fractures in the childhood, while they occupy the first place with $60 \%$ including the elbow circumference fractures (1). The incidence of supracondylar fracture was reported to be 1.8 in $1000(1,2)$.

Supracondylar fractures are divided into two types as extensor and flexor. Extension type fractures are more frequent and particularly visible after palm falls, when the elbow is hyperextended (3). With many classifications being defined, the Wilkins-modified Gartland classification system is the most commonly used system for the classification of extension type supracondylar humerus fractures (3). There are three types in this class: type 1 covers non-displaced humerus fractures; posterior cortex is intact and angulation at varying degrees is present in type 2 ; and cortical integrity is completely lost in type 3 (3).

Most supracondylar humerus fractures occur in 5 to 7 -yearold children (4). Although many techniques in treatment such as traction, casting after closed reduction, open reduction and internal fixation are used, the most commonly used one is closed reduction and percutaneous Kirschner wire (K-wire) technique $(4,5)$. In this study, we aimed to evaluate the clinical results of displaced supracondylar humerus fractures treated by percutaneous K-wire following closed reduction.

Cite this article as:Acar E, Memik R. Surgical Treatment Results in Pediatric Supracondylar Humerus Fractures. Eurasian J Emerg Med. 2020;19(1):25-9. 


\section{Materials and Methods}

A written informed consent was obtained from each patient. The study was approved by the Necmettin Erbakan University Faculty of Medicine Ethics Committee and was conducted in accordance with the principles of the Declaration of Helsinki (protocol no: 2017/950).

In this study, 32 patients who were surgically treated by medial and lateral cross-sectional K-wire between December 2012 and June 2015 due to Gartland type 3 humeral supracondylar fractures were retrospectively analyzed. A detailed medical history was obtained from each patient and their relatives. In addition, local and systemic examinations of the patients were also performed. No additional injury and neurovascular deficit were present in any of the patients. Patients who were scheduled for surgical treatment by evaluating their two sided radiographs of both elbows were included in the study (Figure 1). The patients underwent operation within the first 12 hours, unless there was an obstruction to emergency surgery. All patients under general anesthesia were operated by a single surgeon. For closed reduction, medial or lateral displacement of the distal segment relative to the humerus shaft was corrected after longitudinal traction was applied to the forearm under the guidance of scopy. Then, while the elbow was at 120 degrees of flexion and the forearm was in pronation, the thumb was pressed against the olecranon to provide its reduction. After the reduction was controlled by assessment of front and rear views under the fluoroscopy, the fixation was performed by cross K-wire. Firstly, K-wire at lateral position was sent, then the ulnar nerve was secured under the thumb and medial K-wire was sent, when the medial epicondyle was palpated. Afterwards, fixation of the fracture was seen under the fluoroscopy control (Figure 2). Postoperative long arm was splinted. Postoperative X-ray imaging was performed (Figure 3). A dressing was suggested to the patient and their relatives every three days. On day 7 , all patients were scheduled for the first follow-up visit. There was no loss of reduction with the radiographs taken (Figure 4). According to the X-ray results in the third week (Figure 5), the splints were removed and the elbow movements were started. At four weeks, the K-wires of all patients were removed in the outpatient setting (Figure 6). According to the literature data, a rehabilitation program was administered to the patient by the parents at home, and the range of motion was examined at six weeks and three months after the operation. After the third month, those who returned to normal range of motion were scheduled for followup at 6,12 , and 18 months postoperatively (Figure 7).

In our study, radiological parameters, cosmetic and functional results were evaluated. On the functional evaluation; the flexion, extension, internal and external rotation grades of both arms were examined. The difference between the intact elbow and the operated elbow was assessed by measuring and collecting flexion and extension values. The difference between the good elbow and the operated elbow according to the amount of motion angle was functionally excellent at 0-5 degrees, good at 6-10 degrees, fair at 11-15 degrees, and poor at 15 degrees when the Flynn criteria were applied (Table 1).

For the cosmetic evaluation, the carrying angle from both arms was measured by using a goniometer with McRae method. The difference was regarded as the loss of the carrying angle. The carrying angle loss was assessed by cosmetic criteria based on Flynn's evaluation criteria and the angle ranges used for functional evaluation were performed.

\section{Statistical Analysis}

Statistical analysis was performed using the Statistical Package for the Social Sciences (SPSS) Statistics for Windows, Version 17.0 (SPSS Inc., Chicago, IL, USA). Descriptive data are primarily presented as means. The chi-square test was used to compare the qualitative data of the patients. Statistical significance was defined at the $5 \%(p<0.05)$ level.

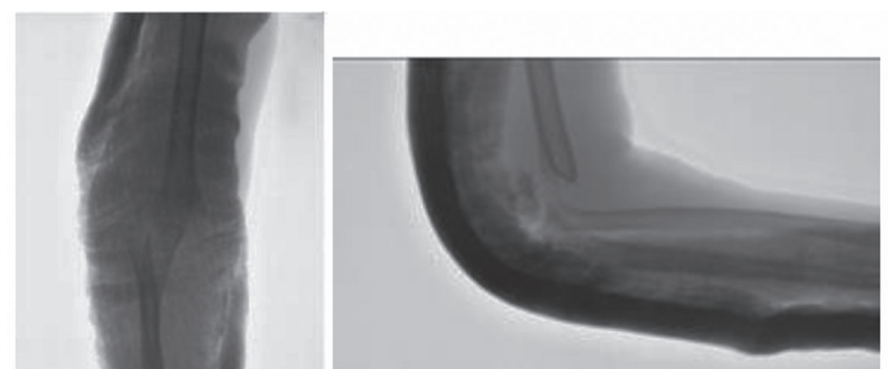

Figure 1. Preoperative supracondylar fracture X-rays (AP and lateral)

AP: Anterior and posterior

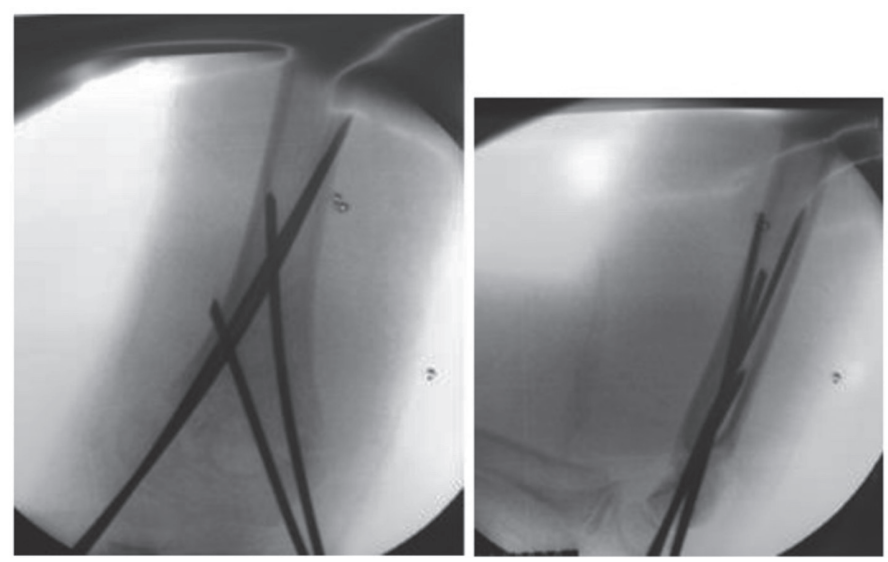

Figure 2. Intraoperative view (AP and lateral) AP: Anterior and posterior 


\section{Results}

Of the patients, 24 (75\%) were male and eight (25\%) were female. The mean age was 6.5 years (range: 2 to 12 years). The mean time to discharge was 1.5 days (range: 1 to 3 days). No postoperative neurovascular deficits were observed.
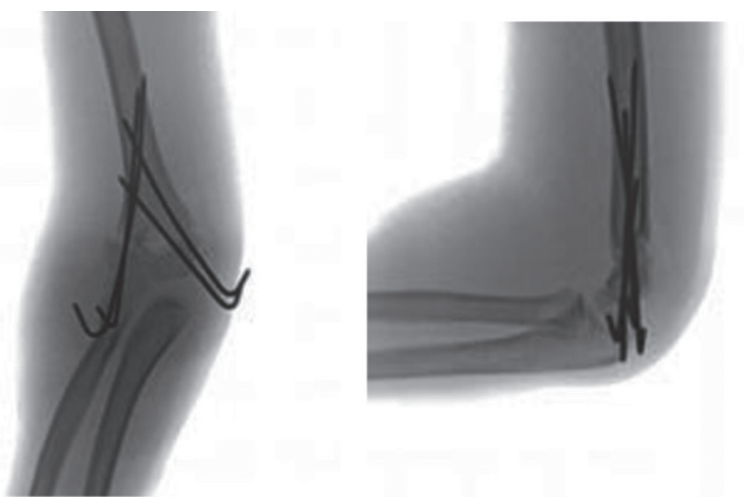

Figure 3. Postoperative X-rays (AP and lateral)

AP: Anterior and posterior
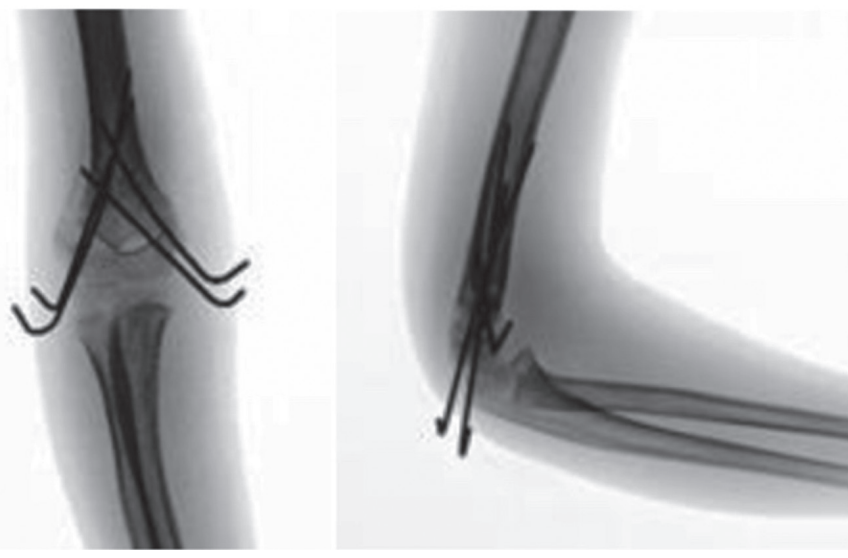

Figure 4. Postoperative first week X-rays (AP and lateral)

AP: Anterior and posterior
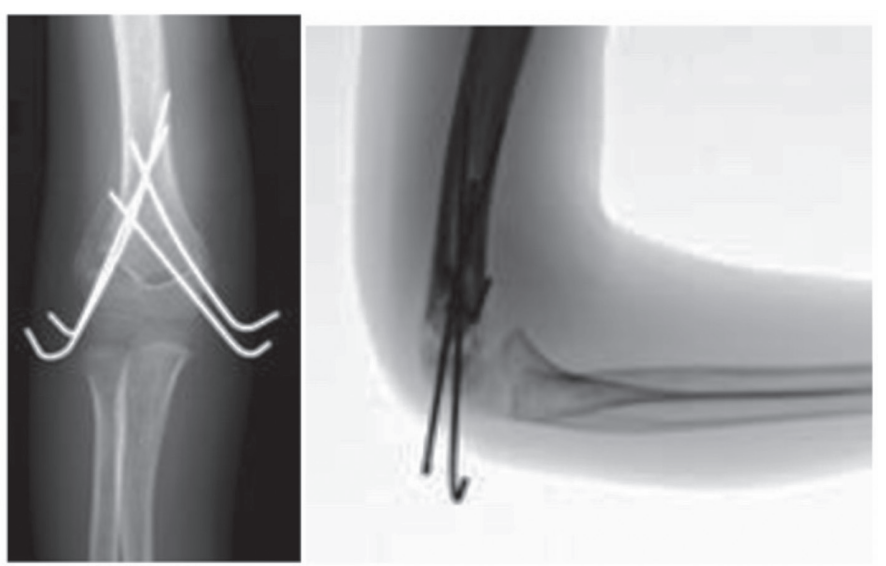

Figure 5. Postoperative third week X-rays (AP and lateral) AP: Anterior and posterior
The mean time to removal of the K-wire during follow-up was 4 weeks. The mean follow-up was 19 months (range: 13 to 26 months). Twelve patients had a simple domestic fall, whereas the fracture developed after the fall in 20 of them while playing outside the home. The functional result according to the Flynn criteria was excellent in $93.4 \%$ and good in $6.6 \%$ patients, while cosmetic results were excellent in $93.4 \%$, good in $5.2 \%$, and fair in $1.4 \%$. Bone union was not considered as a problem on radiological evaluation. None of the patients developed any complication during follow-up.
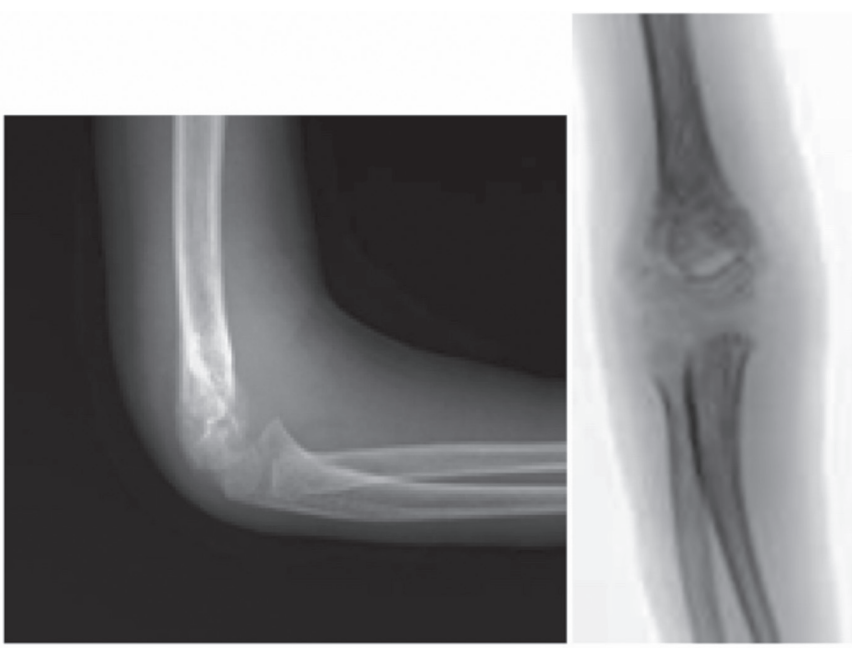

Figure 6. Postoperative forth week X-rays (AP and lateral) AP: Anterior and posterior
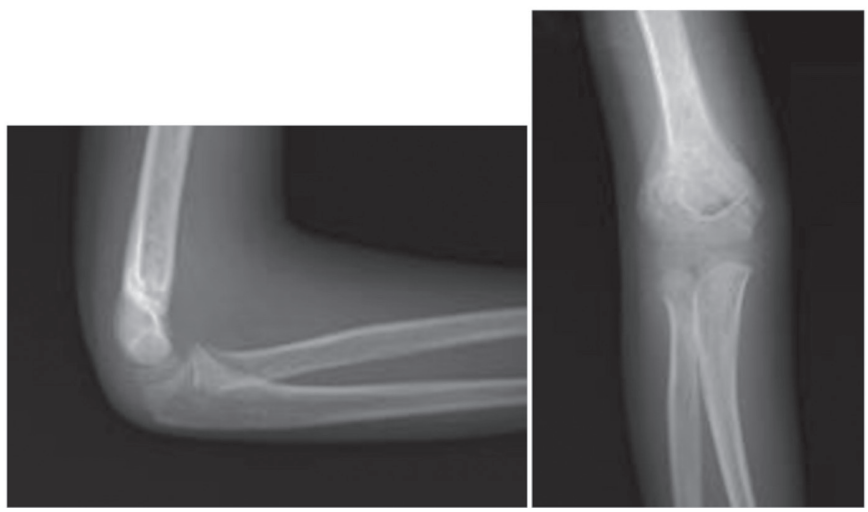

Figure 7. Postoperative eighteenth month X-rays (AP and lateral) AP: Anterior and posterior

\begin{tabular}{|l|l|l|}
\hline \multicolumn{2}{|l|}{ Table 1. Flynn Criteria } \\
\hline & $\begin{array}{l}\text { Change in carrying } \\
\text { angle of cosmetic } \\
\text { factor (degree) }\end{array}$ & $\begin{array}{l}\text { Movement loss } \\
\text { of functional } \\
\text { factor (degree) }\end{array}$ \\
\hline Excellent & $0-5$ & $0-5$ \\
\hline Good & $6-10$ & $6-10$ \\
\hline Fair & $11-15$ & $11-15$ \\
\hline Poor & $>15$ & $>15$ \\
\hline
\end{tabular}




\section{Discussion}

The most common cause of injury in children is falling. Children protect themselves by falling on the hand while the upper extremity is in extension position. This reflex mechanism causes injury to the upper extremity. The distal radius is affected most frequently whereas the elbow is affected as second most. Injury rate is seen to be frequent in elbow injuries in the first two periods if age groups are classified as 3-6 years (preschooler), 7-11 years (schooler), and 12-14 years (teenager) (1,2). In children, supracondylar humerus fractures account for $60 \%$ of the elbow fractures. In general, supracondylar humerus fractures are two times more common in males than females $(1,6)$. In this study, supracondylar fractures all occurred as a result of falling. In addition, these types of fractures were seen three times more in males and the mean age of fractures was 6.5 years.

The main goal of treatment in supracondylar humerus fractures in children is the full acquisition of elbow movements as well as protection of the patient from any possible neurovascular complications, while obtaining an elbow with cosmetically normal appearance. Review of the literature reveals that there are many publications related to the method of closed reduction and percutaneous wiring. Ekșioğlu et al. (7) compared closed reduction and percutaneous K-wire methods with open reduction and internal fixation. In the aforementioned study, it was emphasized that although closed reduction and percutaneous K-wire technique had less traumatic characteristics due to the fracture line not opening, the open reduction and internal fixation method in closed non-reducible cases is a treatment method that can achieve as successful results as closed reduction and percutaneous wiring with the advantages of allowing the fractured line to be seen with full anatomical reduction and reducing the risk of iatrogenic vessel and nerve injury. In the study performed, $80.84 \%$ of patients with closed reduction and percutaneous fixation reported excellent and good results in cosmetic evaluation while $80.95 \%$ of them had excellent and good results in functional evaluation. Open reduction was not required, as all fractures in our study were treated with closed reduction. As a result, in accordance with the literature, patients had excellent and good cosmetic and functional results.

latrogenic ulnar nerve injury can be observed when K-wire is placed from medial side during performing closed reduction and percutaneous K-wire (8), Lyons et al. (9) detected that 19 ulnar nerve lesions occurred postoperatively and reported that 17 of them recovered in a study in which retrospectively evaluated 375 cases treated with closed reduction and percutaneous K-wire were included. Moreover, ulnar nerve lesions resolved spontaneously after surgery; however, if these lesions persisted after 4 months and there were EMG findings, they suggested that exploration could be performed. No ulnar nerve lesions were observed in the present study.

Biomechanical studies have demonstrated the requirement for cross K-wire use to obtain maxillary stabilization in pediatric supracondylar humerus fractures. Eralp et al. (10) compared the results of fixation with a third wire and a conventional crossfixation in addition to cross K-wire fixation. As a result of that study, they reported that they achieved more stable fixation with three wire configurations. Likewise, it was determined in biomechanical studies that stable fixation was obtained from cross K-wire fixation, whereas performing additional K-wire from lateral side increased the stability (5,11-13). As seen in the current study, not only the application of cross K-wire, but also more stable fixation with additional K-wire from lateral side were performed. It is also possible that the fixation can be further stabilized by applying two K-wires medially and laterally. Furthermore, Zionts et al. (14) reported that the most durable composition of K-wire was two crossed K-wires performed medially and laterally. In the present study, cross K-wire was applied in all fixations, suggesting that stabilization was sufficient.

\section{Study Limitations}

The implications of this study are limited due to its retrospective design and the relatively small number of patients. In addition, Gartland type 2 fractures and T type fractures were excluded from the study.

\section{Conclusion}

Closed reduction and percutaneous K-wire, which is a well-known treatment method, is accepted as the most current and reliable method. Satisfactory results according to the Flynn criteria were obtained with medial-lateral cross K-wire placement following closed reduction suggesting that it was safe and acceptable to apply the K-wires transversely following closed reduction with preservation of the ulnar nerve in pediatric displaced supracondylar humerus fractures.

\section{Ethics}

Ethics Committee Approval: The study was approved by the Necmettin Erbakan University Faculty of Medicine Ethics Committee and was conducted in accordance with the principles of the Declaration of Helsinki.

Informed Consent: A written informed consent was obtained from each patient.

Peer-review: Internally peer-reviewed. 


\section{Authorship Contributions}

Surgical and Medical Practice: E.A., R.M., Concept: E.A., R.M., Design: E.A., R.M., Data Collection or Processing: E.A., R.M., Analysis or Interpretation: E.A., R.M., Literature Search: E.A., R.M., Writing: E.A., R.M.

Conflict of Interest: No conflict of interest was declared by the authors.

Financial Disclosure: The authors declared that this study received no financial support.

\section{References}

1. James HB. Rocwood \& Wilkin's Fractures in children. Fifth Edition, Lippincot Williams \& Wilkinson. 2001;563-624.

2. Houshian S, Mehdi B, Larsen MS. The epidemiology of elbow fracture in children: analysis of 355 fractures, with special reference to supracondylar humerus fractures. J Orthop Sci. 2001;6:312-5.

3. Heal J, Bould M, Livingstone J, Blewitt N, Blom AW. Reproducibility of the Gartland classification for supracondylar humeral fractures in children. J of Orthop Surg. 2007;15:12-4.

4. Omid R, Choi PD, Skaggs DL. Supracondylar humeral fractures in children. J Bone Joint Surg Am. 2008;90:1121-32.

5. Karapinar L, Oztürk H, Altay T, Köse B. Closed reduction and percutaneous pinning with three Kirschner wires in children with type III displaced supracondylar fracture of the humerus. Acta Orthop Traumatol Turc. 2005;39:23-9.
6. Erol B, Bezer M, Er G, Karahan M, Guven 0. The management of elbow fractures in children. Marmara Medical J. 2004;17:93-8.

7. Ekșioğlu F, Güdemez E, Sepici B. Çocuk suprakondiler deplase humerus kırıklarında açık redüksiyon internal fiksasyon yöntemi ile kapalı redüksiyon perkütan çivileme yönteminin karşılaștııılması. Artroplasti Artroskopik Cerrahi. 2000;11:173-8.

8. Otsuka NY, Kasser JR. Supracondylar fractures of the humerus in children. J Am Acad Orthop Surg. 1997;5:19-26.

9. Lyons JP, Ashley E, Hoffer MM. Ulnar nerve palsies after percutaneous crosspinning of supracondylar fractures in children's elbows. J Pediatr Orthop. 1998;18:43-5.

10. Eralp L, Demirhan M, Dikici F, Önen M. Deplase humerus suprakondiler kırıklarının tedavisinde çapraz Kirschner teli ve üç tel konfigürasyonlarının radyolojik olarak karşılaştırılması. Acta Orthop Traumatol Turc. 2000;34:27883.

11. Larson L, Firoozbakhsh K, Passarelli R, Bosch P. Biomechanical analysis of techniques for pediatric supracondylar humerus fractures. J of Pediatric Orthop. 2006;26:573-8.

12. Bloom T, Robertson C, Mahar AT, Newton P. Biomechanical analysis of supracondylar humerus fractures pinning for slightly malreduced fractures. J of Pediatric Orthop. 2008;28:766-72.

13. Brauer CA, Lee BM, Bae DS, Waters PM, Kocher MS. A systematic review of medial and lateral entry pinning versus lateral entry pinning for supracondylar fractures of the humerus. J of Pediatric Orthop. 2007;27:1816.

14. Zionts LE, McKellop HA, Hathaway R. Torsional strength of pin configurations used to fix supracondylar fractures of the humerus in children. J Bone Joint Surg. 1994;76:253-6. 